\title{
Micro Total Analysis Systems: Microfluidic Aspects, Integration Concept and Applications
}

\author{
Albert van den Berg and T.S. J. Lammerink \\ MESA Research Institute, University of Twente, P.O. Box 217, 7500 AE Enschede, \\ The Netherlands.E-mail: A.vandenBerg@el.utwente.nl
}

In this contribution three aspects of miniaturized total analysis systems ( $\mu$ TAS) are described and discussed in detail. First, an overview of microfabricated components for fluid handling is given. A description of the importance of sampling- and fluid-handling techniques is followed by details of microvalves, micropumps and micro flowchannels. Secondly, the problems associated with system integration are discussed. As a solution for the realization of microfluidic- and micro analysis systems, the concept of a planar mixed circuit board (MCB) as a platform for the integration of different components is described. In addition, the design, modeling and simulation, and realization of several components in the form of standard modules for integration on a MCB is described. As an illustration of the potential of this approach, the realization of a $\mu$ TAS demonstrator for the optical detection of the $\mathrm{pH}$ change of a $\mathrm{pH}$ indicator, is presented. Finally, a number of different applications of $\mu$ TAS are described, such as on-line process monitoring, environmental monitoring, biomedical and space applications and DNA-analysis.

Keywords: Microsystem, (bio)chemical analysis, fluid handling, $\mu$ TAS, micropump.

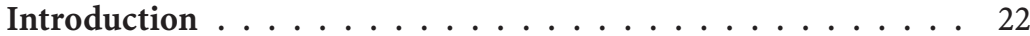

$1.1 \quad$ General ..................... 22

1.2 (Bio)chemical Analysis Systems vs (Bio)Chemical Sensors . . . . 22

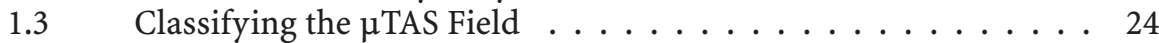

1.4 Elements of a $\mu \mathrm{TAS} \ldots \ldots \ldots \ldots \ldots$

2 Sampling and Fluid Handling ... . . . . . . . . 25

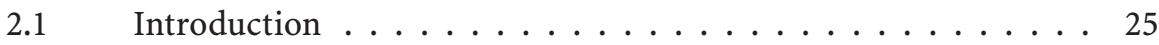

2.2 Sampling Techniques and Components ........... 25

2.3 Fluid Handling Components . . . . . . . . . . . . . 26

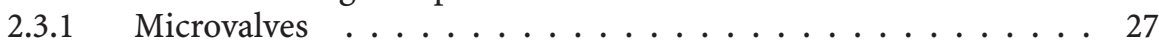

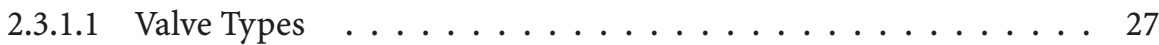

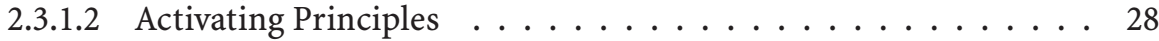

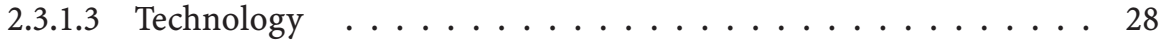

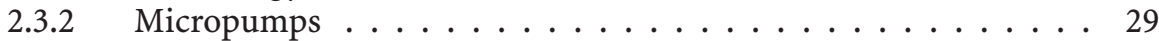

2.3.3 Micro Flowchannels ................. 33

$3 \quad$ System Integration $\ldots \ldots \ldots \ldots \ldots$

3.1 Integration Concepts . . . . . . . . . . . 35

3.2 The Mixed Circuit Board (MCB) Concept . . . . . . . . . . . 37 
$3.3 \quad$ System Modules . . . . . . . . . . . . . . . . . . 37

$3.4 \quad$ Modeling and Design $\ldots \ldots \ldots \ldots \ldots \ldots$

3.4.1 Thermal Flow Sensor . . . . . . . . . . . . . . . . . . 38

3.4.2 Thermopneumatic Micropump . . . . . . . . . . . 41

3.5 Realization of a Demonstrator System _ . . . . . . . . . 43

3.5 .1 Despcription . . . . . . . . . . . . . . . 43

3.5.2 Results . . . . . . . . . . . . . . . . . 43

$4 \quad$ Applications $\ldots \ldots \ldots \ldots \ldots \ldots \ldots \ldots \ldots$

$5 \quad$ Conclusions $\ldots \ldots \ldots \ldots \ldots \ldots \ldots \ldots \ldots$

$6 \quad$ References $\ldots \ldots \ldots \ldots \ldots \ldots \ldots \ldots$

1

\section{Introduction}

1.1

General

The subject of miniaturized systems for (bio)chemical analysis is attracting increasing attention from researchers in the biochemistry, analytical chemistry, microsensors and microtechnology field. In Europe as well as North America, and to a lesser extent Japan, many groups are actively studying the subject; micro total analysis systems ( $\mu$ TAS) have recently been assigned as a strategic research orientation of the MESA Research Institute of the University of Twente [1]. In this contribution, besides a description of several essential components of such $\mu$ TAS, concepts for their integration, technologies for fabricating them as well as applications are presented and discussed. The main aim of this work is to inform scientists and engineers active in the analytical and biochemistry fields about the possibilities offered by modern (silicon based) microtechnology, triggering them to think about new and innovative measurement methods.

\section{2}

\section{(Bio)Chemical Analysis Systems vs (Bio)Chemical Sensors}

The analysis of the (bio)chemical state of a system is often described in terms of sensors. These (miniaturized) devices convert the (bio)chemical state (chemical concentration, activity or partial pressure of particles such as atoms, molecules, ions etc. [2] into a (mostly) electrical signal. However, recently miniature components such as mixers, filters, separation columns, reactors etc., have been developed $[3,4]$ that are capable of pretreating the sample, carrying out a chemical reaction or separating the different components within a sample mixture. The possibility to integrate such components into one miniaturized system leads to a more generalized view on information gathering (see Fig. 1). In general, in order to simultaneously analyze $\mathrm{N}$ components using a system 


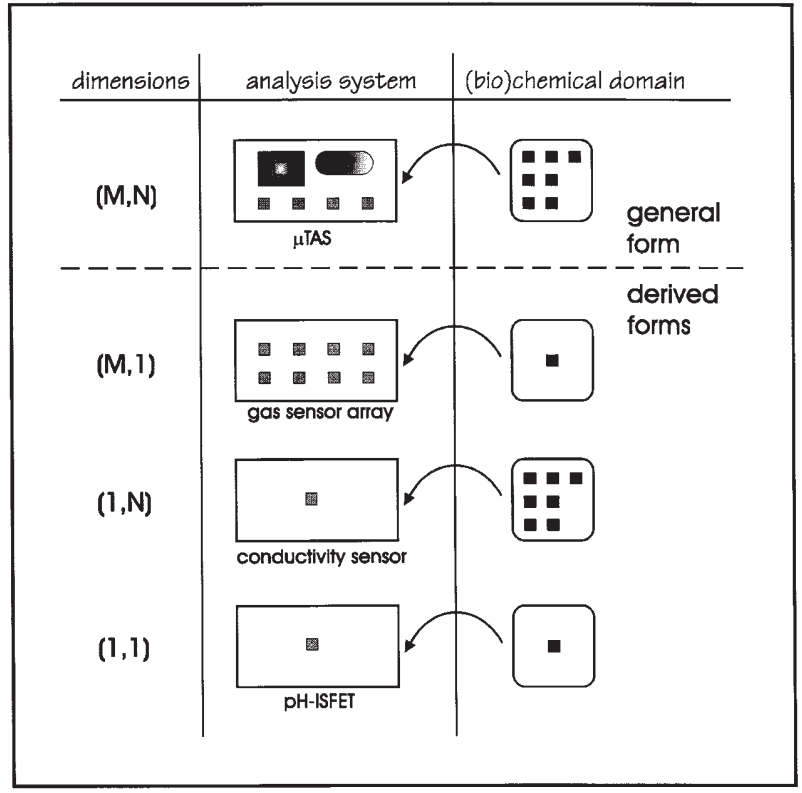

Fig. 1. Transfer of information from the (bio)chemical domain using an analysis system

containing $M$ different sensors, $M$ needs to be larger than N. Special cases are those where $\mathrm{M}$ or $\mathrm{N}$ equals $1 . \mathrm{N}=1$ can be identified with a sensor array where more than one partially selective sensor is used to selectively detect one component in a mixture (e.g. a gas sensor array). $M=1$ is a theoretical case where one analysis system element can be used to detect different (bio)chemical components. As an example, a conductivity sensor can be used to sense the presence of various gases in a gas chromatograph, but not to distinguish them simultaneously. Finally, with $\mathrm{M}=\mathrm{N}=1$, one sensor may be 'perfectly' selective for one component, such as for instance an ion sensitive field effect transistor (ISFET) for $\mathrm{pH}$. The latter case has been most extensively investigated during the past few decades for a large variety of components [5].

The miniaturized analysis system, however, may also contain components that select one component or a class of components from a mixture (filters, reactors) or components that transform the simultaneous presence of $\mathrm{N}$ components in a sequential presence of $\mathrm{N}$ different single components (separation devices). The fact that miniaturized analysis systems contain all elements needed to perform the required analysis is reflected in the term $\mu$ TAS as first quoted by Manz and colleagues in 1990 [6]. The recent strong interest of many research groups in this subject is stimulated by the fact that finding solutions for chemical measurement problems through development of individual sensors for each of the desired parameters has not been very successful up to now. The main reason for this lies probably in the wide variety of parameters and applications, making one general approach for a sensor very difficult. A solution 
for this would be to develop a relatively expensive "overperforming" analysis system instead of a simple sensor. Such a system should be modified for each particular application. Examples of this approach are a micro flow injection analysis system ( $\mu \mathrm{FIA})$ [7] and micro gas chromatograph ( $\mu \mathrm{GC})$ [8]. Once such a standard or "generic" solution is widely accepted, the sensor community can focus its efforts to optimize and economize it. In our view this is the only way to obtain optimal synergy from the present quite diversified activities in this field.

\section{3}

\section{Classifying the $\mu$ TAS Field}

The research and development field of $\mu$ TAS can be differentiated according to several principles. First, the analyte phase (liquid/gas) plays an important role. Clearly, most detection principles can be exclusively used either in the gas or liquid phase. Some detectors, especially those based on thermal principles, can be used in both phases albeit at different ranges of sensitivity. Secondly, the systems can be distinguished according to their mode of operation: flow-type systems or separation-type systems. In the latter type a further differentiation can be made between liquid chromatography and electrophoresis systems. Finally, the application area brings about so many specific requirements that an application-oriented classification seems justified. Examples of application areas are space applications, DNA analysis, and biomedical applications. A classification according to the second criterium appears the most sensible, since the mode of operation influences or even determines the used technology, and is strongly linked to the application as well.

\section{4}

\section{Elements of a $\mu$ TAS}

With the first development of piezo micropumps [9], people started to realize that one day such pumps might be integrated together with sensors into a complete microsystem for chemical analysis. In general, four types of subsystems are thought to comprise a $\mu$ TAS: a sampling unit, a microfluidic unit, a detector system and an electronic controller (see Fig. 2). The aspects of electronic control are too specific to be treated in this contribution. The detector system in a $\mu$ TAS illustrates many problems related to the small size of the system [10]. An important aspect is the very small size required for the sensing element operating in a microchannel of a few hundreds of microns width. Electrochemical sensors for instance suffer from the lack of a properly functioning micro-reference electrode. In the case of ISFETs a differential setup with two spatially separated ISFETs in combination with a quasireference electrode has overcome this difficulty [11]. For optical absorption sensors, widely applied for chemical analysis, the very limited absorption length is the major difficulty. Here, artificially increasing this length by multiple reflection techniques seems the most promising direction. In such a case, using loss-free interference mirrors is preferred over using partly-transparent metal films. Unfortunately, no comprehensive study treating the prob- 


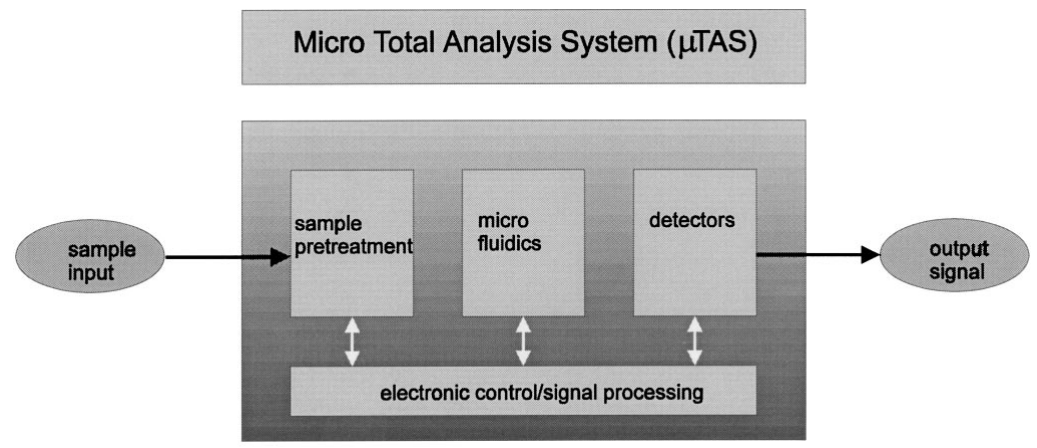

Fig. 2. Elements of a Micro Total Analysis System ( $\mu$ TAS)

lems of miniaturized detector systems has been carried out yet. For this reason we will focus on the sampling and fluidic units and the concept for integration of the different components into one system.

\section{2}

\section{Sampling and Fluid Handling}

\section{1}

\section{Introduction}

For miniaturized analysis systems, taking samples and manipulating them is of great importance. When miniaturizing macroscopic systems, specific problems include representativeness of the sample and reproducibility of small sample manipulation. Thus, in addition to the whole range of sampling techniques already utilized by analytical chemists in conventional systems, specific techniques and components need to be developed. In particular, attention has to be paid to dead volumes, which give rise to tailing effects in chromatography, and surface properties of the fluid channels, that may cause turn-over effects due to the large surface-to-volume ratio.

\section{2}

\section{Sampling Techniques and Components}

An often underestimated subsystem in miniaturized analyzers is the sampling part. This subsystem incorporates an arrangement that guarantees a representative part of the analyte to be prepared and transported into the analyzer's fluid handling part. The configuration of the analysis system determines the constraints for the sampling. When using silicon micropumps comprising microvalves, for instance the presence of particles (e.g. dust particles, sand grains, living cells) is prohibited because they block the valves. The sampling subsystem should therefore contain a microfilter which may consist of a conventional polymer membrane (e.g. a MilliPore filter) or a microfabricated 


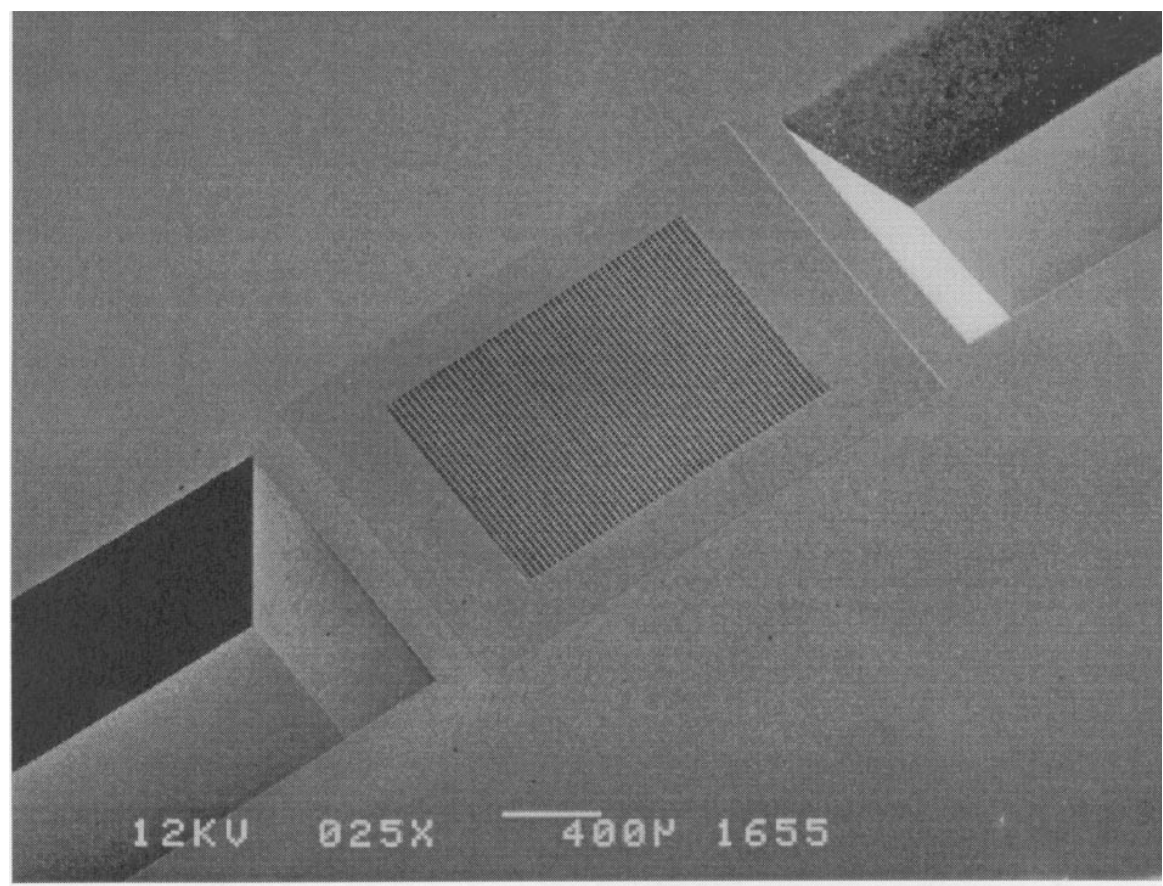

Fig. 3. Micrograph of a silicon microfilter

silicon filter [12] (see Fig. 3). The latter filter has several advantages over conventional (polymer) ones. It has a uniform pore size, low pressure loss, and very small internal volume. Furthermore, it may be used in a setup for rapid (microscale) mixing [13].

In microdialysis sampling, polymeric membranes are used to filter out large biomolecules and cells from the analyte. This technique, introduced some ten years ago, has now become a standard technique in neurochemical laboratories $[14]$ and seems to be well-suited for combination with $\mu$ TAS $[15,16]$. The great advantage of coupling this sampling technique to a $\mu$ TAS is that the internal system volume (comprising connections) remains limited. This means that in spite of flow rates in the order of less than $1 \mu \mathrm{l} / \mathrm{min}$, a high sample throughput can be obtained.

\section{3}

\section{Fluid Handling Components}

Several review articles describing miniaturized devices for fluid handling have been published that give excellent and detailed overviews of the state of the art $[3,4]$. Here, some examples of microfabricated valves and pumps will be given to illustrate the possibilities of silicon microtechnology. 


\subsection{1}

\section{Microvalves}

\subsubsection{1}

\section{Valve Types}

If we consider a valve as a controlled restriction in a fluid flow channel the following types can be distinguished:

Type A The first type consists of a plane surface which moves in a direction perpendicular to the flow coming from an orifice (Fig. 4 a). We can have a circular orifice surrounded by a valve seat and a plane surface which moves parallel to the valve seat until the flow is shut off.

Type B The second type consists of the channel being constricted (Fig. 4b).

Type $C$ The third type is somewhere in between and consists of two mating parts, like the ground glass stopper mated to the neck of bottles used to store chemicals. The mating parts move into each other thereby constricting the flow channel (Fig. 4c).

Type D A new type of valve is formed by freezing and melting of a part (plug) of a fluid passage. This type is also called the micro electro thermo fluidic (METF) valve [17]. The main advantage of this type of valve is the completely zero dead volume and absence of moving parts.

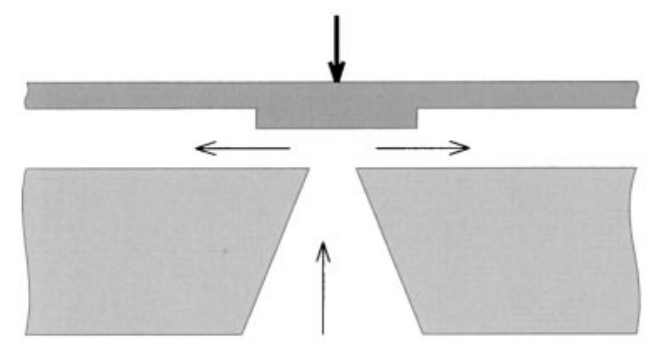

Fig. 4 a. Valve type A; restriction perpendicular to fluid flow

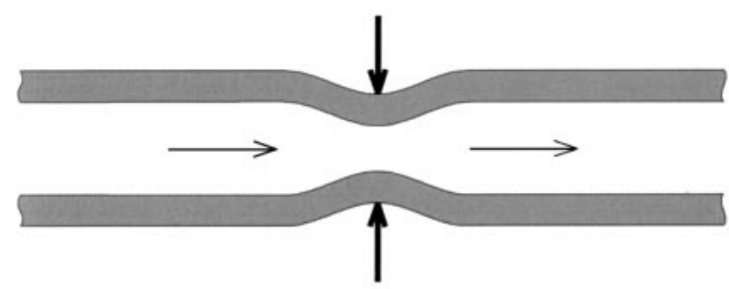

Fig. 4 b. Valve type B; restrication parallel to fluid flow 


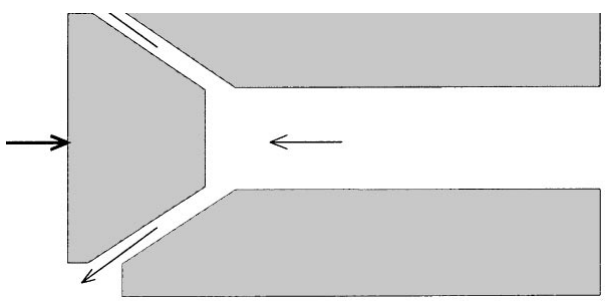

Fig. 4 c. Valve type C; combination of valve type A and B

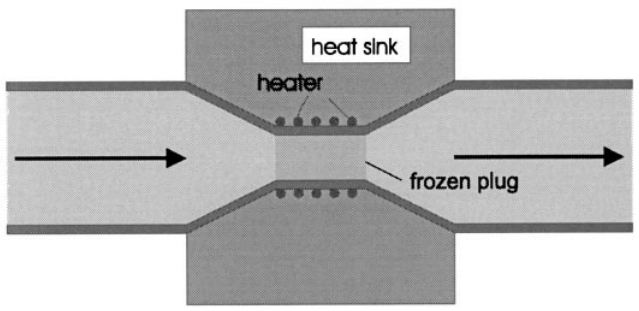

Fig. $\mathbf{4}$ d. Valve type D; Restriction is formed by frozen part of the liquid

\subsubsection{2}

\section{Activating Principles}

For all types of valves, the parts have to move toward or from each other and therefore an actuator is needed. Although there is no power needed to shut off a flow in the ideal case, this is not true in practice. Controlling a flow (i.e. keeping the constriction in its place in a closed loop configuration) requires a power source, while shutting off a flow requires power to overcome friction or to overcome pressure built up at the orifice during the action. Often a closed valve of type $\mathrm{A}$ is secured by a differential pressure. This pressure must be overcome to open the valve. An important requirement in any design is whether the valve should be open or closed when the power goes down (some valves have more than one stable position). From this requirement the valve types 'normally open' and 'normally closed' can be distinguished.

\subsubsection{3}

\section{Technology}

It cannot be denied that the work on microvalves is in its infancy and it is impossible to classify the valves with respect to the technology used in its production. However, most of the micromachined valves fabricated to date use silicon micromachining. In exceptional cases also other techniques such as LIGA (Lithograpfie, Galvanoformung, Abformung; a technique involving lithography electrodeposition and molding) may be used [18]. 


\subsection{2}

\section{Micropumps}

The classification of micropumps is somewhat arbitrary. One might distinguish micropumps according to the type of momentum transfer to the solution (mechanical or electrical), but for practical reasons, we choose here to distinguish them by the presence or absence of mechanical valves, this being a generic element of many pumps. A second classification can be made using the actuation principles (see Fig. 5). Various examples of the different pump-types are listed below.

\section{Valve-type Micropumps.}

Piezoelectric Actuation

The very first work on micropumps using piezoelectric actuation was on a peristaltically functioning micropump, which was not published until 1990 [19]. In this micropump, momentum is given to the fluid by a row of valves which give the effect of a restriction moving in the direction of the desired flow. The general structure of a pump with one actuator using two check valves is shown in Fig. 6. A number of check valve type micropumps, all realized using a micromachined silicon wafer anodically bonded to Pyrex glass, have been developed

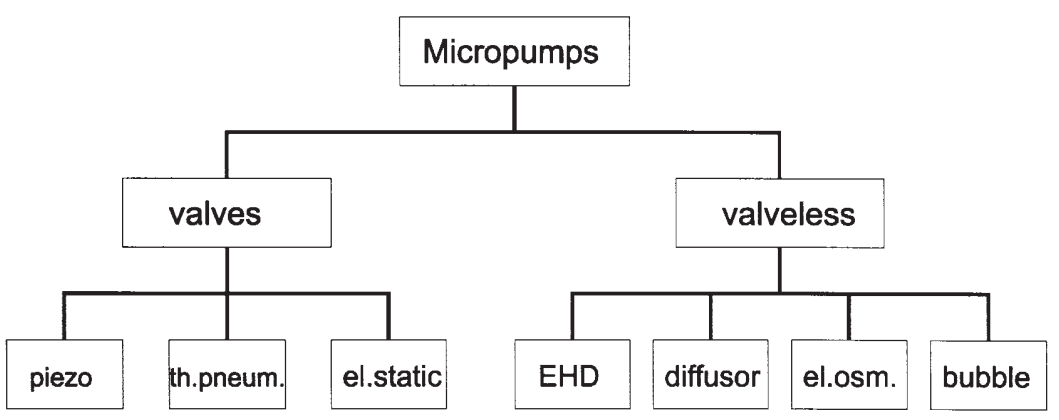

Fig. 5. Classification of micropumps

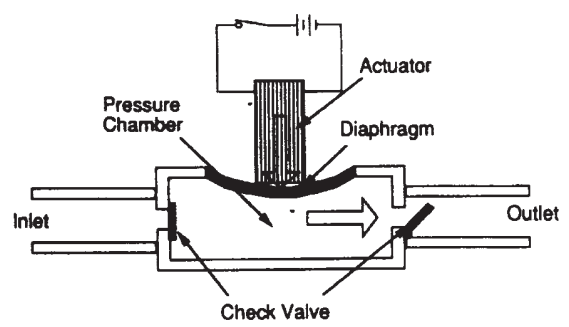

Fig. 6. Principle of check-valve micropump with piezoelectric actuation 
at Twente University $[9,20,21]$. The check valves in these pumps are round membranes with orifices and valve seats and they open and close as a consequence of the pressure caused by the driving actuator. In the first model, the driving actuator consists of a bimorph formed by a thin glass membrane and a commercial piezo disc. The seats of the check valves have a surface layer in order to prevent bonding of the check valves when the wafers are bonded. The extra layer is also advantageous in that it give the check valve a small pre-stress.

After the initial work at the University of Twente, other groups optimized [22, 23] or modified [24] piezoelectric actuated micropumps and probably the most advanced micropump to date is the bi-directional one presented by Zengerle et al. [25]. This pump uses an external piezo-actuator and has a complex, actuation frequency dependent mode of operation which creates bi-directional pumping as a function of frequency. The pump has unprecedented specifications: flow rates up to $2 \mathrm{ml} / \mathrm{min}$ ( $8 \mathrm{ml} / \mathrm{min}$ for gas), pressure up to $17,000 \mathrm{~Pa}$, bi-directionality and self-priming, which makes this pump actually the best performing one. Unfortunately, contrary to what many researchers have been aiming at during the past few years, there appears to be a growing demand for very precise pumping and dosing in the nanoliter range for applications such as drug delivery and DNA analysis.

\section{Thermopneumatic Actuation}

An alternative actuation principle is thermo-pneumatic actuation, as illustrated in Fig. 7. Heating of a confined gas, or gas/liquid mixture, leads to expansion of the gas which deforms a flexible membrane covering the pump chamber. Compared to piezoelectric actuation, the voltages used for heating are much lower, making this pump much more suitable for combination with electrochemical sensors. Even more important is that this design can be fully batch fabricated, be it at the cost of a number of extra silicon and glass wafers forming a six layer stack. Typical yields of this pump are between 10 and $100 \mu \mathrm{l} / \mathrm{min}$ with maximum pressures up to $10,000 \mathrm{~Pa}$. In the operating region of the pump with a counter pressure built up, no measurable backflow occurs, indicating that the closure of the valves is very good. The limiting counter pressure is not deter-

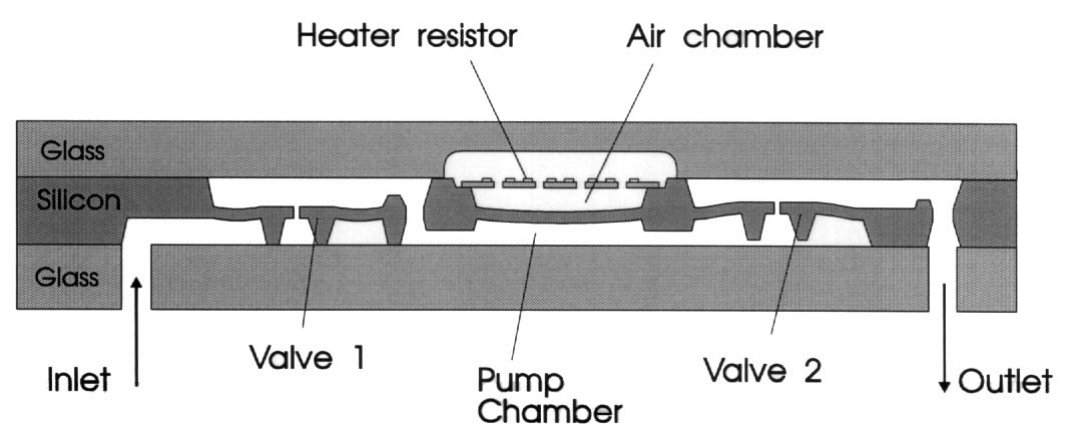

Fig. 7. Principle of a thermopneumatic micropump 


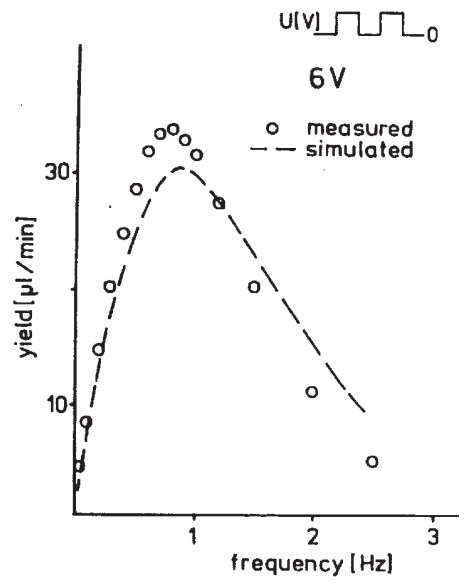

Fig. 8. Pump yield as function of pump frequency for an applied voltage of $6 \mathrm{~V}$ at zero back pressure (outlet minus inlet pressure)

mined by backflow but by the pressure balance within the device. In Fig. 8 the measured as well as the simulated [26] pump yield as a function of actuation frequency is shown.

\section{Electrostatic Micropumps}

Finally we present a design of Zengerle et al. [27], based on an electrostatic driving principle. A thin pump membrane electrode is electrostatically repelled from a fixed counter electrode (see Fig. 9). The design contains a stack of four wafers. Here, there is a clear trade off between driving pressure (requiring a small electrode gap, but staying out of the "pull in" regime) and output stroke (requiring a large electrode gap). Quite high voltages are needed to get a reasonable output flow, but the counter pressure that can be overcome with this design is still rather small. However theory predicts a better performance than the experiments show. Again a frequency, much higher than in the thermopneumatic design can be reached giving a smoother outflow.

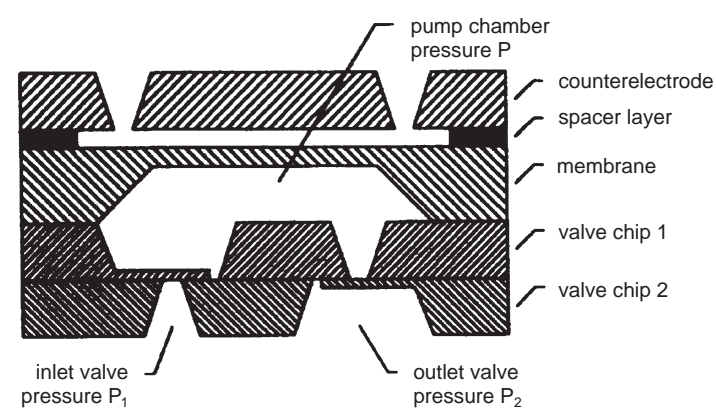

Fig. 9. Principal design of the electrostatically actuated membrane pump [from ref. 27] 
Electrohydrodynamic (EHD) Micropumps

The EHD pump of Richter et al. [28, 29] is an example of the "body force"pump. In fact the driving force is created by large electric fields created between two grids, which are positioned orthogonal to the flow direction, or by induction $[30,31]$. When using electrodes, a short distance is required to create the necessary high fields, which must be high enough to generate ions at the first grid, which are driven by Coulomb forces and drag the fluid in this driving direction. The process of ionization is complex and depends on electrode material, liquid composition and voltage. With induction pumping, gradients in permittivity or conductivity in the liquid are required. EHD pumps have no moving parts, which is a clear advantage, but it can be imagined that the counter pressure is limited. 'Backflow' immediately occurs when the driving force is shut off. Unfortunately, aqueous solutions cannot be pumped as a consequence of the high ionic conductivity.

\section{Electroosmotic Force Pumping}

This pumping principle relies on the presence of (immobile) surface charges in glass capillaries. At neutral $\mathrm{pH}$ values, the surface of glass (silanol groups) are negatively charged, and positive (mobile) counterions align along the inside of the capillary. When a high voltage is applied the mobile counterions start to move, and take the rest of the fluid column with them.

\section{Electroosmotic flow (EOF)}

This type of pumping is frequently employed in separation chemistry for capillary electrophoresis, traditionally in fused silica capillaries, but recently more and more in planar quartz structures [32-34]. It should be noted that this type of pump is of the current-source type. This means that the pressures that can be obtained depend on the internal resistance; in wide glass tubing, with little resistance, very little pressure can be built up, and a very small hydrostatically induced differential in/outlet pressure immediately overrules the electroosmoticpumping. However, in very small capillaries, relatively high pressures can be obtained (up to tens of bars).

\section{Diffuser Pumps}

An original pumping principle without moving valves was presented by Stemme et al. [35, 36]. It consists of an actuated pump chamber and diffuser/nozzle elements, that take care of a rectifying action. The principle of operation relies on the fact that the pressure drop Dp over a diffuser/nozzle can be written as:

$$
\mathrm{Dp}=\mathrm{ru}^{2 *} \xi / 2
$$

Where $\mathrm{r}$ is the fluid density, $\mathrm{u}$ is the mean fluid velocity, and $\xi$ is the pressure loss coefficient. The latter coefficient is different for a diffuser and a nozzle, so that the pressure loss depends on the direction of the fluid flow. After a first version 
made by conventional machining techniques, a micromachined version was realized which gave yields of $40 \mathrm{ml} / \mathrm{min}$ of water and a zero-flow pressure of $50 \mathrm{~cm} \mathrm{H}_{2} \mathrm{O}$.

\subsection{3}

\section{Micro Flow Channels}

Recently there has been a great deal of interest in the fabrication of microchannels in planar substrates. Several etching techniques in silicon (e.g. isotropic and anisotropic wet etching) have been investigated for this purpose. Recently, deep reactive ion etching (DRIE) [37] has been developed as a new technique to make vertical channels with relatively high aspect ratios in silicon (Fig. 10). Vertical channels allow a high density of channels per unit area and therefore provide a long (vertical) absorption path length for optical detection. The high channel density is illustrated by a channel structure for chromatography containing over $300 \mathrm{~m}$ of $2.5 \mu \mathrm{m}$ wide and $25 \mu \mathrm{m}$ deep channels on one single $3^{\prime \prime}$ wafer (see Fig. 11).

The wafers containing the etched trenches are anodically bonded to Pyrex glass to form closed channels. The bond strength thus formed is strong enough to withstand pressures up to 250 bar. At that point a breakdown even takes place in the monocrystalline silicon and not at the bonded interface. Clearly, the indicated structures are useful for HPLC applications.

However, for capillary electrophoresis typically voltages of several $\mathrm{kVs}$ are applied, and completely isolating materials such as quartz are used [32]. Unfortunately, wet etching of quartz is not trivial, and little is known about dry

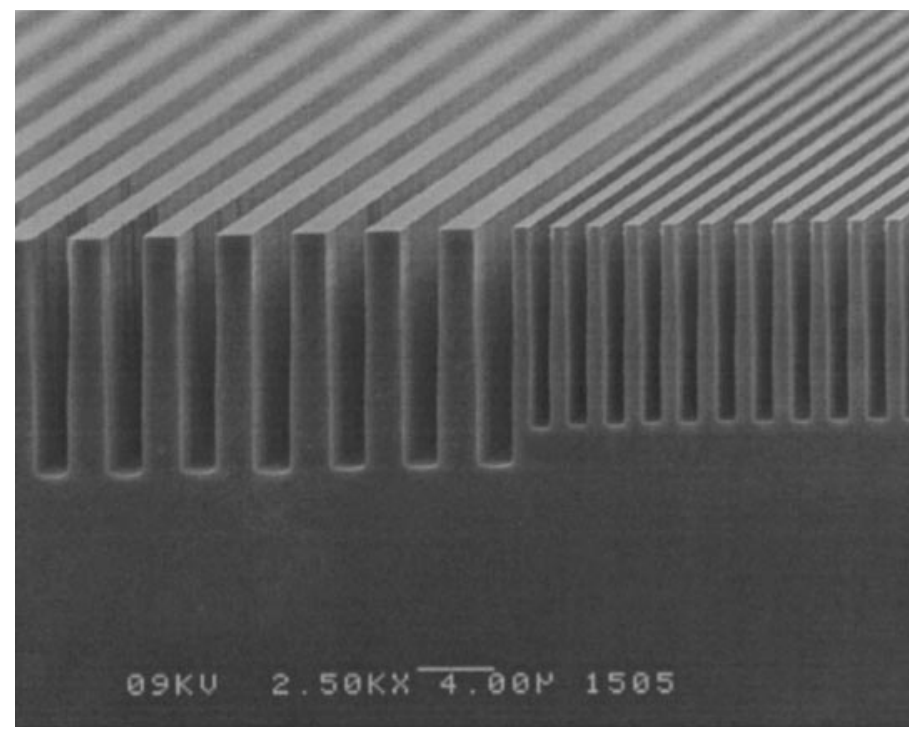

Fig. 10. Vertical channels in silicon made with DRIE 


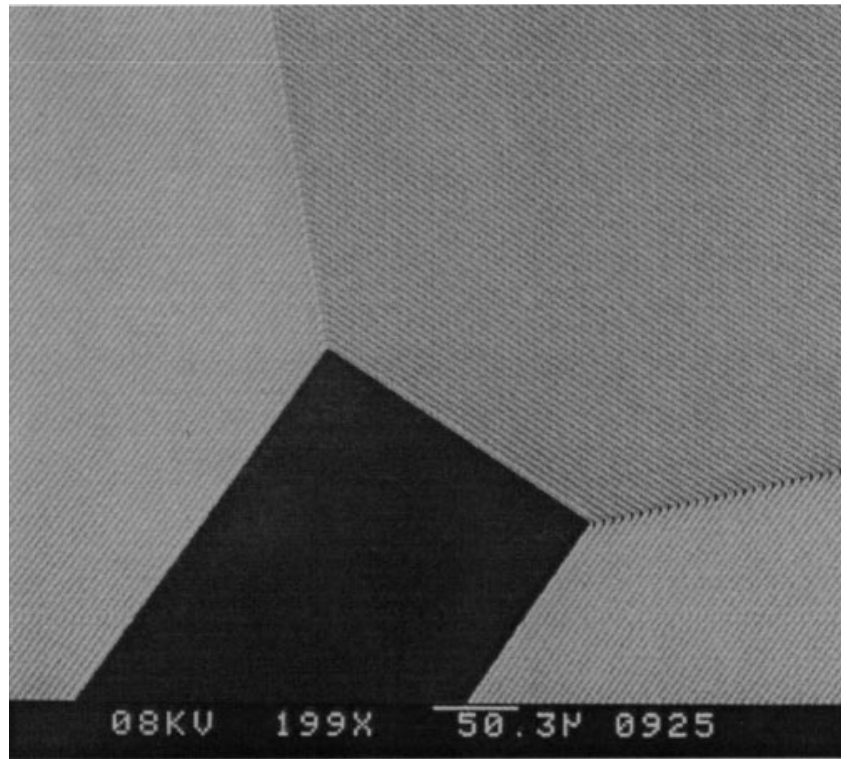

Fig. 11. Anisotropically etched microchannels for chromatography

etching techniques of quartz. It is therefore interesting to transform the etched silicon structures into isolating structures. For this purpose, the etched trenches are filled with silicon oxide and anodically bonded. Subsequently, the reverse side of the silicon is etched back until the oxide is reached, and in such way closed, all-glass microchannels are formed (see Fig. 12).

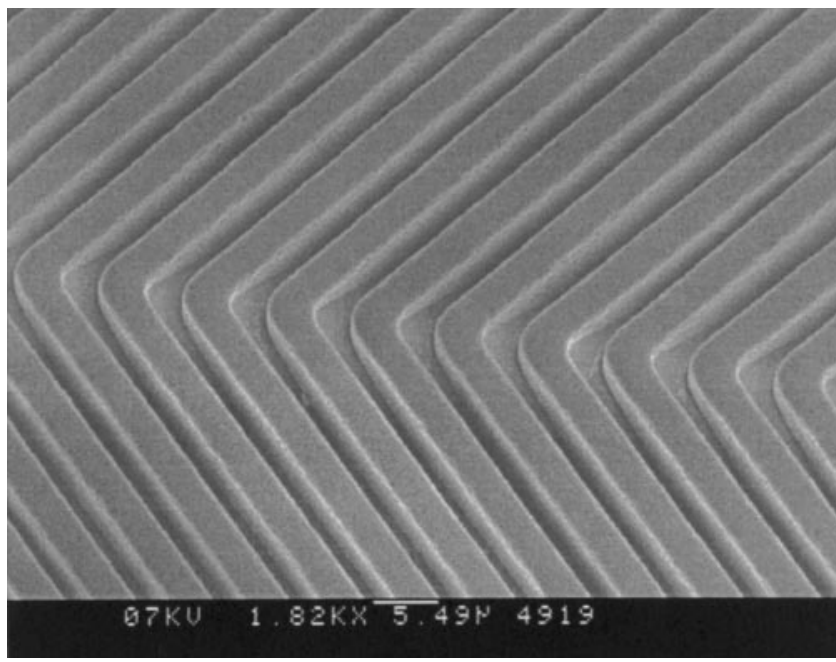

Fig. 12 a. All-glass microchannels formed by DRIE with back-etched silicon 


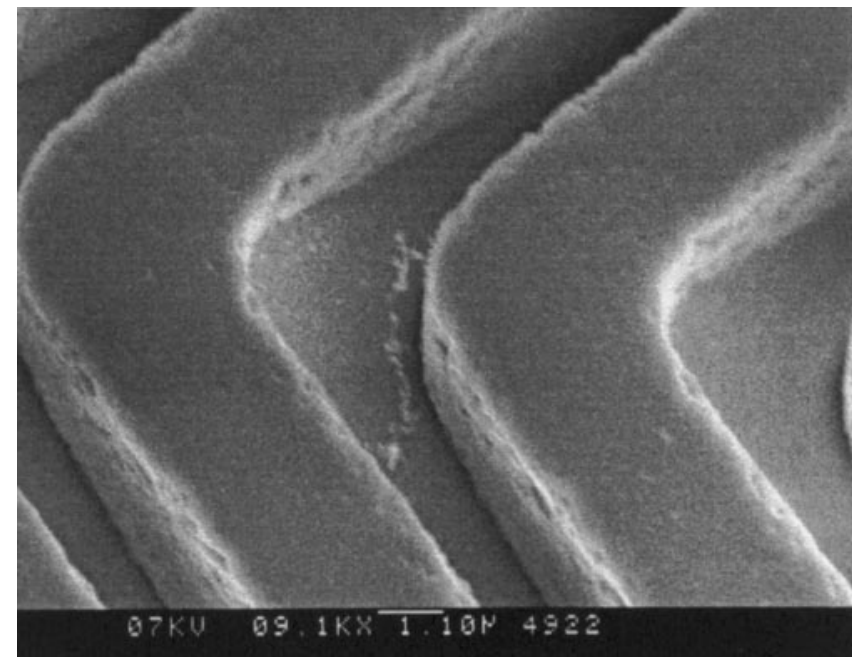

Fig. 12 b. Detailed micrograph of glass-microchannels

\section{3}

\section{System Integration}

\section{1}

\section{Integration Concepts}

$\mu$ TAS configurations often comprise a large variety of components, such as optical, electrochemical, micromechanical and electronic ones. It is clear that covering all the needed expertise for building such a $\mu$ TAS is hardly possible for one company or institute. Thus, it should be possible to combine components or subsystems from different developers/suppliers into one microsystem, for which, evidently, some sort of standardization is needed. In addition, although for almost every microsystem a natural tendency exists to look for monolithic integration, as for instance illustrated in the micro liquid dosing system of Lammerink et al. [20], new functions usually start as hybridly integrated components, so that a real life system typically is a mixture of monolithically integrated subsystems and separate components (Fig. 13). Thus, there is a clear need for a flexible concept for microsystem integration.

Two different approaches have been explored for integration of $\mu$ TAS. The first approach is to use vertical stacking of components [38, 39]. This builds further on the original disc-stacking concept of Ciba Geigy [40], where planar system components or modules with fixed size are stacked onto each other. The liquid is transported from one module to another through on-module deposited micro sealing rings [5]. An alternative approach is to mount the different system modules on a horizontal baseplate. This method guarantees a better compatibility with standard pick-and-place techniques usually employed for the realization of electronic circuits. 


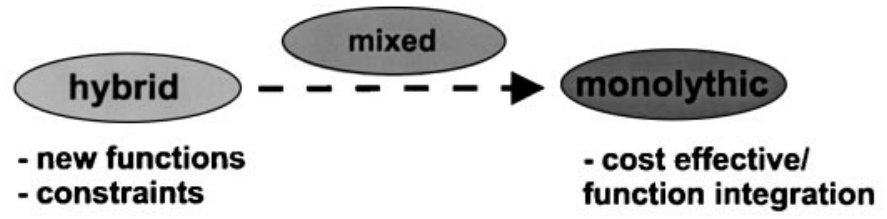

Fig. 13. Possibilities for $\mu$ TAS integration

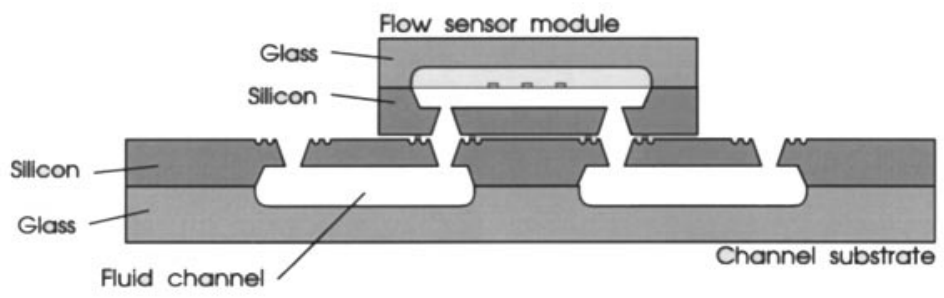

b

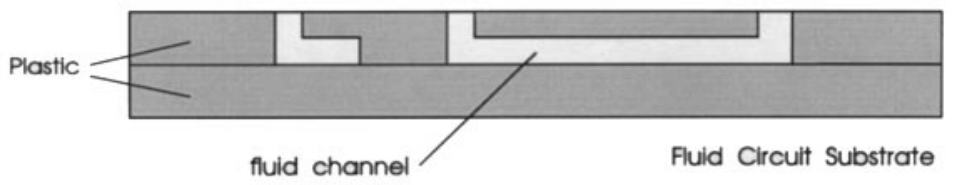

c

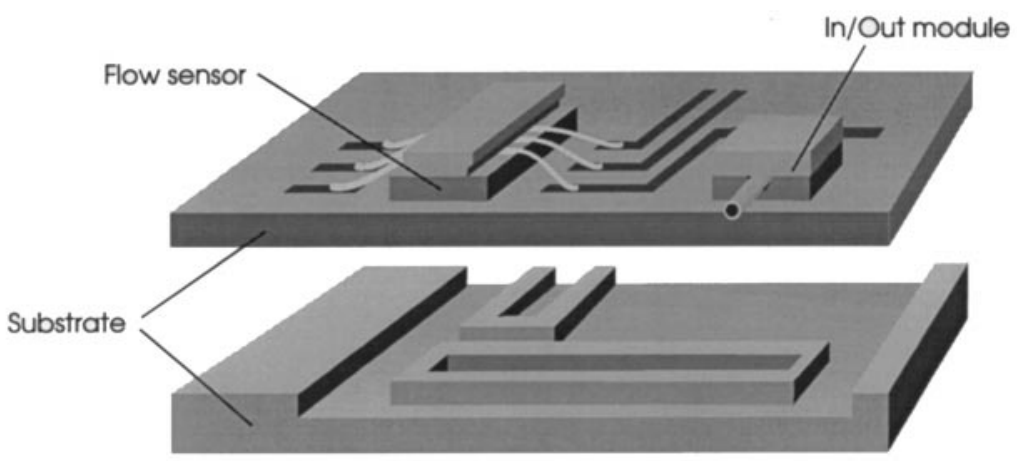

Fig. 14.

Planar modular concept for fluid handling micro-systems with functional modules on top of a Mixed Circuit Board

a Flow sensor on top of a silicon-glass $\mathrm{MCB}$,

b MCD made of plastics,

c 3D-view of MCB with flow sensor and input/output 


\section{2}

\section{The Mixed Circuit Board (MCB) Concept}

Figure 14 shows schematic diagrams of the so-called mixed circuit board (MCB) which generally consists of two parts to form the fluid channels. The MCB may be built by a glass-silicon sandwich but also by plastics. The modules can be attached with the help of existing bonding techniques such as anodic bonding, glue and soldering. The demonstrated MCB consist of an epoxy printed circuit board attached to a transparent polycarbonate substrate. Versions with machined channels in either one or the other part are used. The top surface of the MCB contains the electric connections and holes for fluid transport from and to the channels. Future developments of the MCB similar to the developments in the printed circuit board technology like flexible versions are feasible.

\section{3}

\section{System Modules}

For the realization of fluid handling microsystems a wide variety of modules is needed. Many of them, like pumps, flow sensors and filters, have already been developed, as described in Sect. 2.3. However, for integration of these components into a system, it was necessary to design them anew. All designs were based on a standard port pitch of $5 \mathrm{~mm}$. Figures 15 to 18, illustrate SEM and/or optical photographs of several system modules.

\section{4 \\ Modeling and Design}

Because of the enormous diversity in components it is difficult to describe a straightforward design-path for components for the MCB concept. Here we focus on the modeling and the design of the fluid control modules and specific on the thermo-pneumatic actuated micropump used (twice) in the demonstrator. An elaborated model of this micropump is given by van de Pol et al. [21]. The main functions of the fluid control in micro analysis systems are the switching function and the direct flow and/or pressure control. Building blocks are hydraulic inertances, resistors, capacitors and passive and control-valves. Very often an active element like a micropump is needed.

The approach adapted in our group is based on finite element modeling (FEM) in combination with lumped element modeling. FEM is used for specific (mono-, duo-) domain problems. Although the encountered geometries can be rather complex, FEM is not the appropriate tool for modeling the whole system (multi-domain) behavior. The FEM modeling results in specific lumped parameters (e.g., stiffness, capacitance, fluid resistance) which are subsequently used in a lumped element system model. This lumped element system modeling and simulation tool is based on the bond graph description language. Practical implementation of the modeling and simulation is done using the 20SIM program package [26]. 

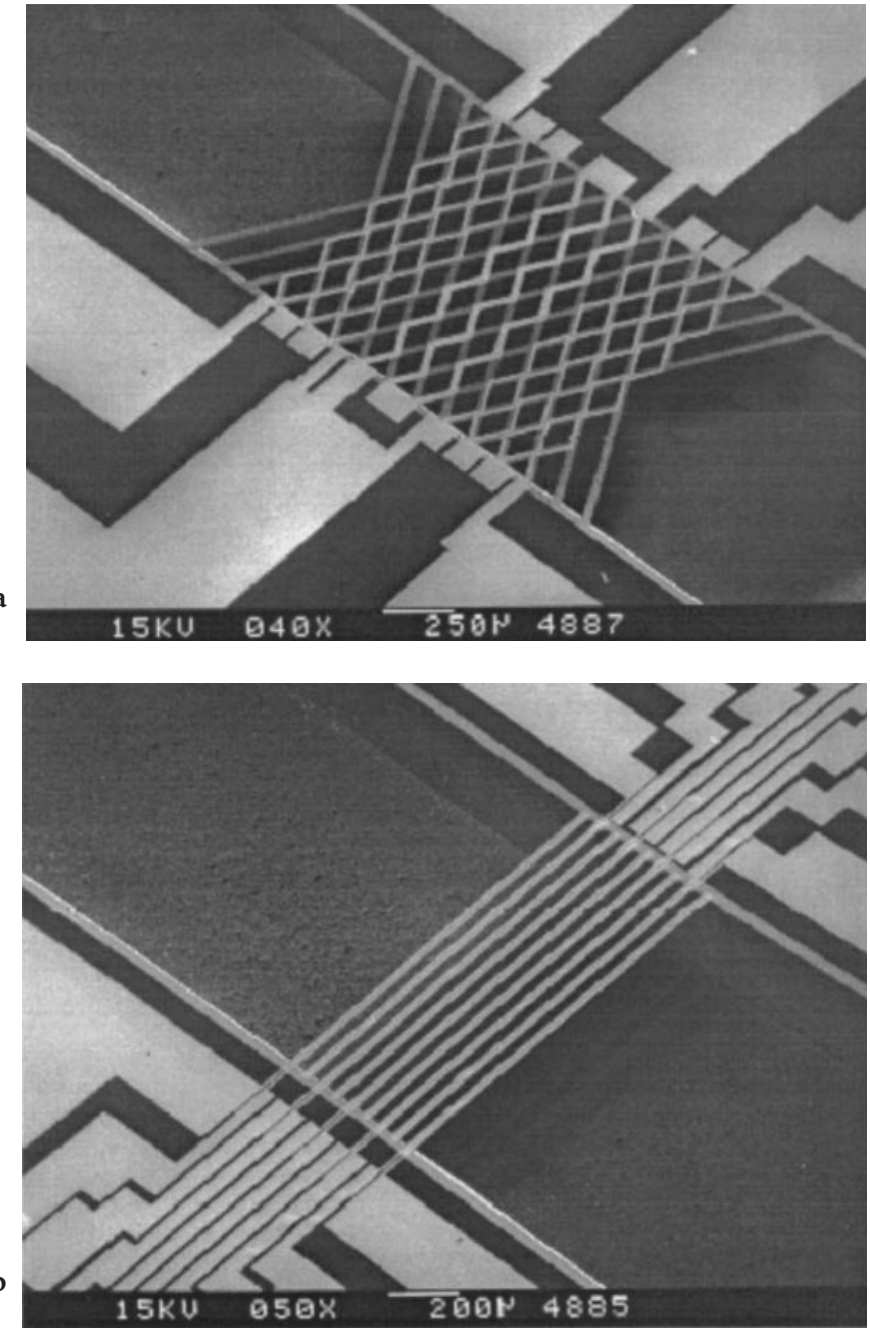

Fig. 15. a Grid type flow sensor, b beam type flow sensor (the fluid channel width is $1 \mathrm{~mm}$ )

The modeling of a thermopneumatic micropump is given as an example of this approach. Simulation results as well as design aspects of a microsystem containing two of these micropumps are discussed.

\subsection{1}

Thermal Flow Sensor

The demonstrator fluid handling system contains two thermal micro flow sensors illustrated in Fig. 19. Three resistors are located in the middle of the flow channel. 


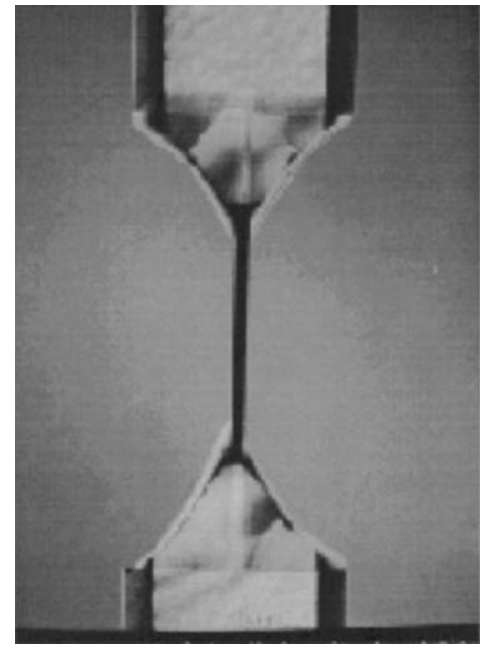

Fig. 16. Hydraulic resistor made of anisotropically etched V-groove
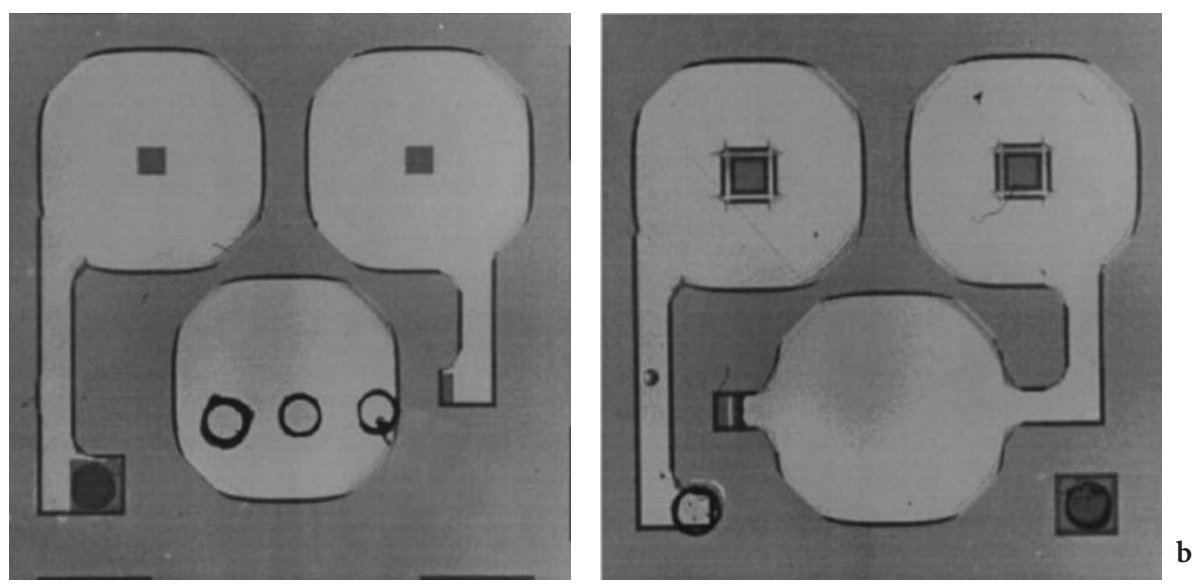

Fig. 17. a Micropump (top) and b micropump (bottom)

Heat is dissipated in the middle resistor $(\mathrm{H})$. The resulting temperature distribution is sensed with two temperature sensitive resistors $T_{u}, T_{d}$ located symmetrically up- and downstream with respect to the heater. The temperature difference $\Delta \mathrm{T}$ as function of the flow shows a maximum which limits the usable flow range of the sensor. A typical output signal of the flow sensor is given in Fig. 20. 

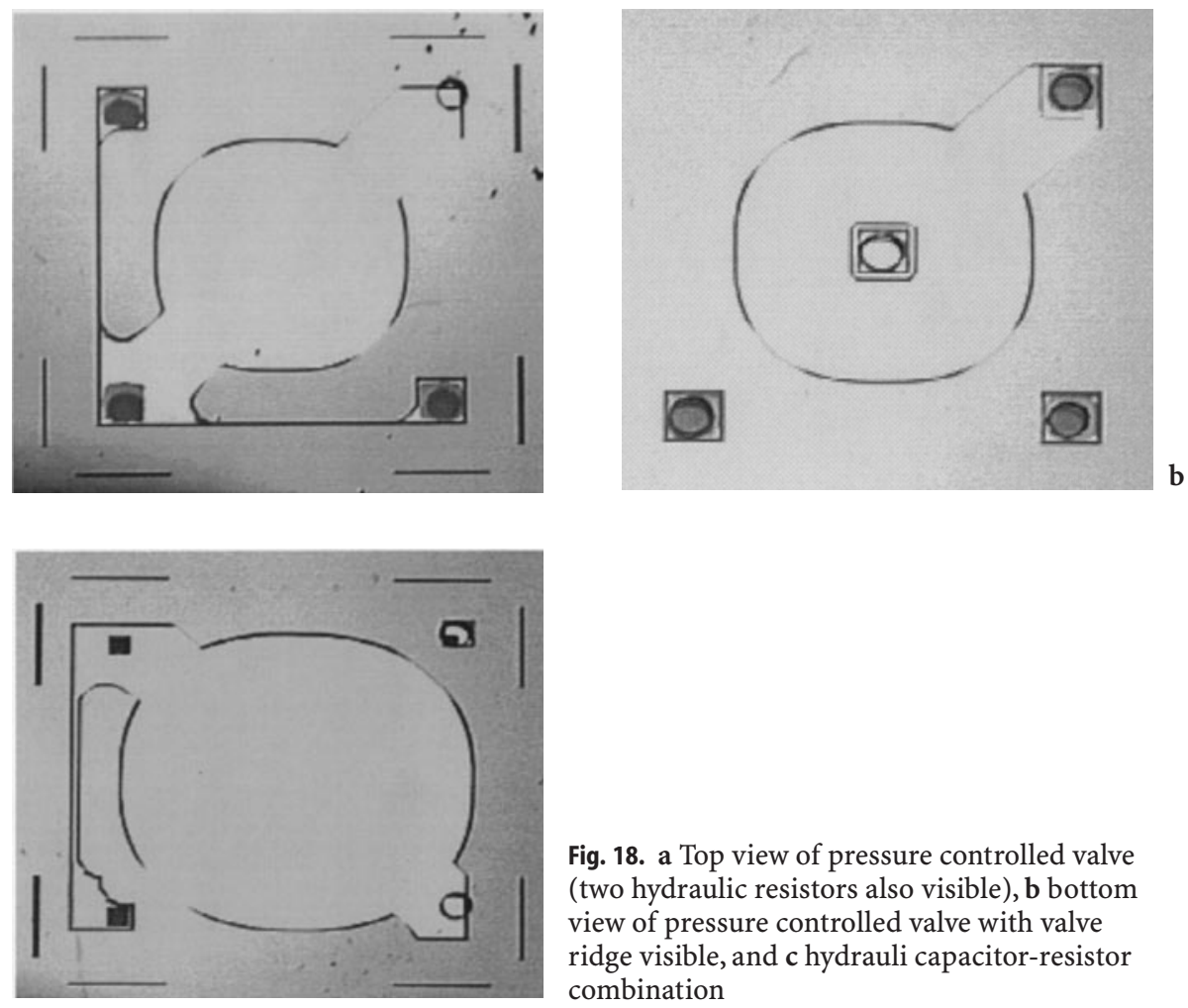

Fig. 18. a Top view of pressure controlled valve (two hydraulic resistors also visible), b bottom view of pressure controlled valve with valve ridge visible, and $\mathrm{c}$ hydrauli capacitor-resistor combination

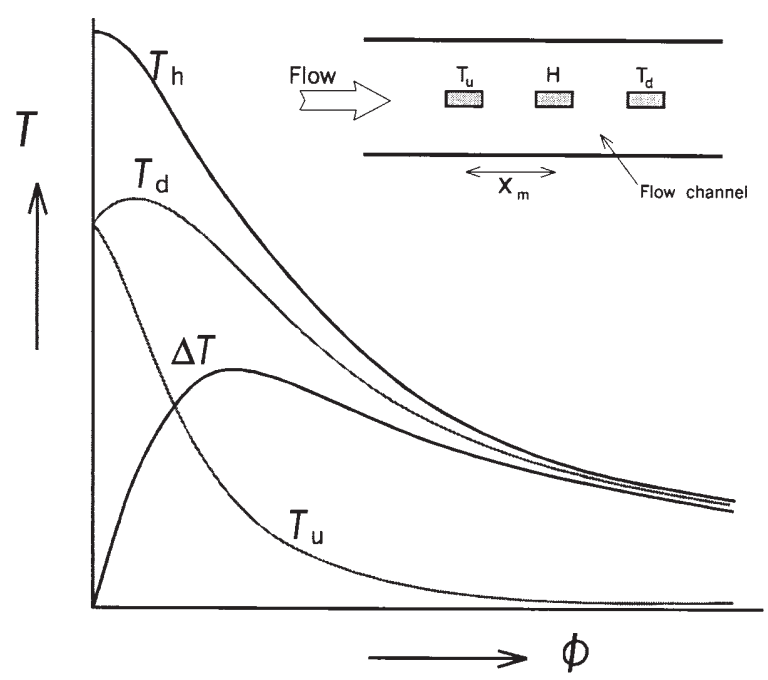

Fig. 19. Resistor temperatures as function of the flow with constant power dissipation in the heater resistor. The insert shows the layout of the thermal flow sensor with three resistive elements in the center of the flow channel 


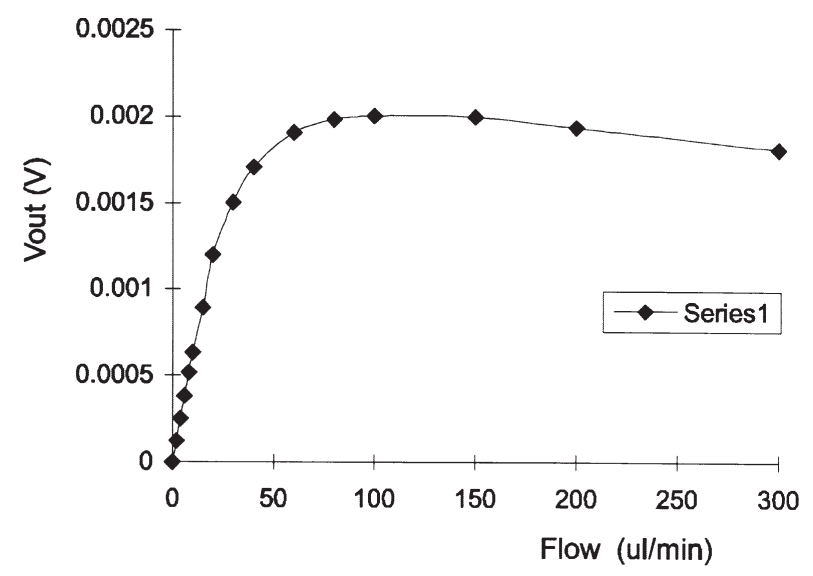

Fig. 20. Typical flow sensor output signal as function of the flow. (For sensor geometry see figure 19; $10 \mathrm{~mW}$ dissipation in the heater resistor; $1 \mathrm{~mW}$ in the sensor restistors; $150 \Omega$ ). The sensor can be used op to $100 \mu \mathrm{l} / \mathrm{min}$ (ethanol)

\subsection{2}

\section{Thermopneumatic Micropump}

The demonstrator analyzing system contains two thermo-pneumatic actuated micropumps (see Fig. 7). The micropumps are of the reciprocating type and consist of three main building blocks: a thermo pneumatic actuator (A), a pump chamber with a flexible pump membrane which acts as a capacitor (C) and two passive circular silicon check valves (V), see Fig. 21.

The pump actuator generates a periodically varying pressure in the air chamber. This pressure acts on a flexible pump membrane between actuator and pump chamber. Due to the deflection of the pump membrane the volume of the pump chamber changes. By means of two check valves, the liquid is periodically sucked in through one valve and forced out through the other valve, thus forcing a flow into one direction. The thermopneumatic actuator consists of a cavity filled with air and a thin film heating resistor supported by thin silicon nitride beams for (periodically) heating the gas inside.

A narrow air channel connects the cavity to the outside and allows a pressure exchange with the surroundings. A typical actuator does have a circular air chamber with a diameter of $8 \mathrm{~mm}$ and a height of $400 \mu \mathrm{m}$ with the resistor mounted in the middle between "floor" and "ceiling". The "thermal" response (warming up and cooling down of the air) can be described with a "thermal" relaxation time $\tau_{t}$ which is mainly determined by the heat capacity of the heaterresistor and the heat conductivity of the gas [21]. A second relaxation time is determined by the heat capacity of the whole pump body and the heat conductivity of the body to its surroundings. Due to the air channels there is also a (third) 'pneumatic' relaxation time $\tau_{\mathrm{p}}$. Since the pneumatic system is non-linear, $\tau_{p}$ can only be approximated. 


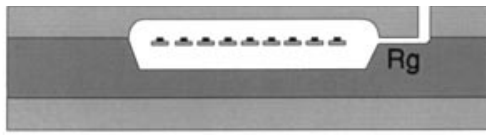

A
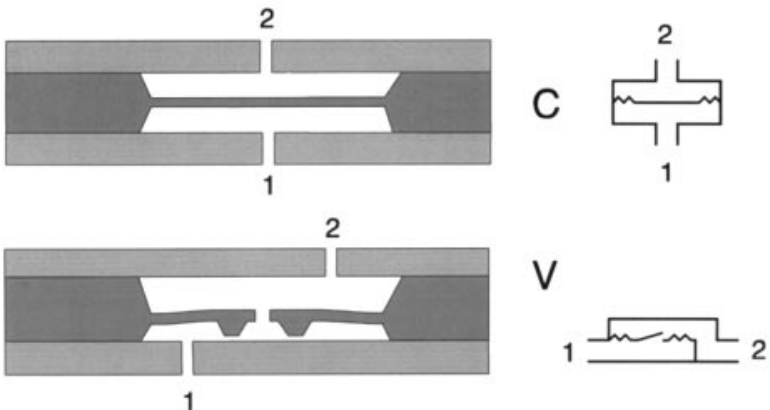

Fig. 21. Cross sections of the glass-silicon-glass structures for the pump actuator, the pump membrane and the valves. Right from the figures, the so-called Ideal Physical Models (IPM's) of the pump membrane and the valve are given

The pump membrane acts as a capacitor (see Fig. 21, C) which stores a volume, related to a pressure drop. In first approximation the volume change under the membrane is linear with the center displacement [42]. The membrane capacitance, however, shows a strong non-linear behavior for center displacements in the range of large deflections.

The normally closed check valves consist of a flexible outer ring and a rigid inner sealing ridge (see Fig. $21, \mathrm{~V}$ ). When pressure $\mathrm{p}_{1}$ is higher than $\mathrm{p}_{2}$ the sealing ridge is lifted, and liquid flows through the valve. When pressure $\mathrm{p}_{2}$ is higher than pressure $\mathrm{p}_{1}$ the valve is closed. Due to a thin oxide layer on the valve ridge the valve has a small pre-pressure. Obviously, the valve has a strongly non-linear behavior.

The whole micropump is described in a bond graph model [43]. The pump is driven by a (square-wave) heat source. Simulation results of the pump actuation as well as the pump rate based on this model are given in Figs 22 and 23

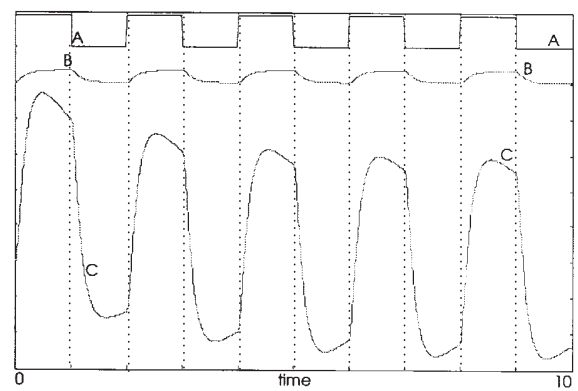

Fig. 22. Simulation of a pump actuator: $\mathbf{A}=$ heating power in $[\mathrm{W}], \mathbf{B}=$ gas temperature in $[\mathrm{K}]$ and $\mathrm{C}=$ gas pressure in the actuator chamber in $[\mathrm{Pa}]$. The thermal relaxation times are 0.2 and $200[\mathrm{~s}]$ and the pneumatic relaxation time is $2[\mathrm{~s}]$ 


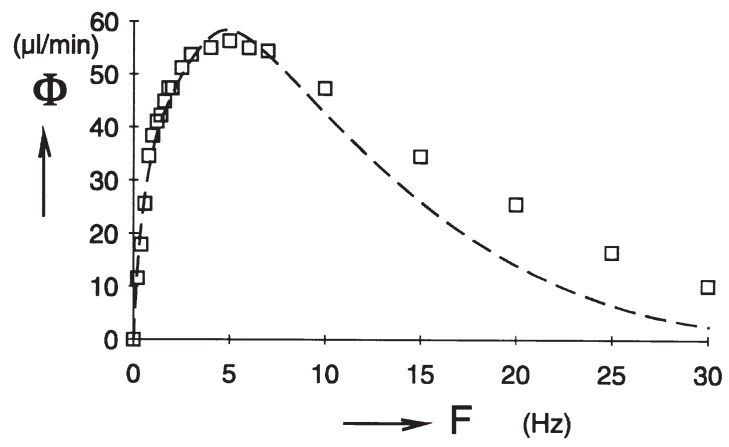

Fig. 23. Simulated and measured pump rate as a function of the excitation frequency. The amplitude of the simulation is fitted with the amplitude of the heating power

respectively. Using the bond graph description language, modeling of more complex systems becomes relatively simple.

\section{5}

\section{Realization of a Demonstrator System}

\subsection{1}

\section{Description}

A schematic diagram of the demonstrator chemical analysis system is given in Fig. 24. The MCB comprises three in/outlets, two micro-pumps, two flow sensors and an optical absorption detector module. The purpose is to measure chemical reaction products by detection of the (spectral) absorption intensity. Sample and reagent liquids are mixed in the appropriate amounts on-board (currently the actual mixing takes place during the propagation in channels) and the optical absorption is measured at the detector side.

The electronic control circuitry is situated in two levels below the MCB layer with the modules. It is based on a microcontroller system for the micro liquid handling and the chemical analysis data. Implemented in the electrical circuitry are driving circuits for the micro pumps, sensing circuits for the flow sensors, optical absorption measurement circuitry, power management and communications using an RS232 interface.

The absorption cell is a glass silicon glass sandwich component $(15 \times 1 \times$ $0.4 \mathrm{~mm}$ ) where optical intensities from different colored LEDs are measured by a 64 pixel CCD detector, see also Fig. 25. A demonstrator system with a total system volume of about $50 \mathrm{ml}$ is illustrated in Fig. 26.

\subsection{2}

\section{Results}

Figure 27 shows test results of the measured pump and flow sensor behavior. The time constant of the pump/flow sensor combination is in the order of $0.2 \mathrm{~s}$. This 

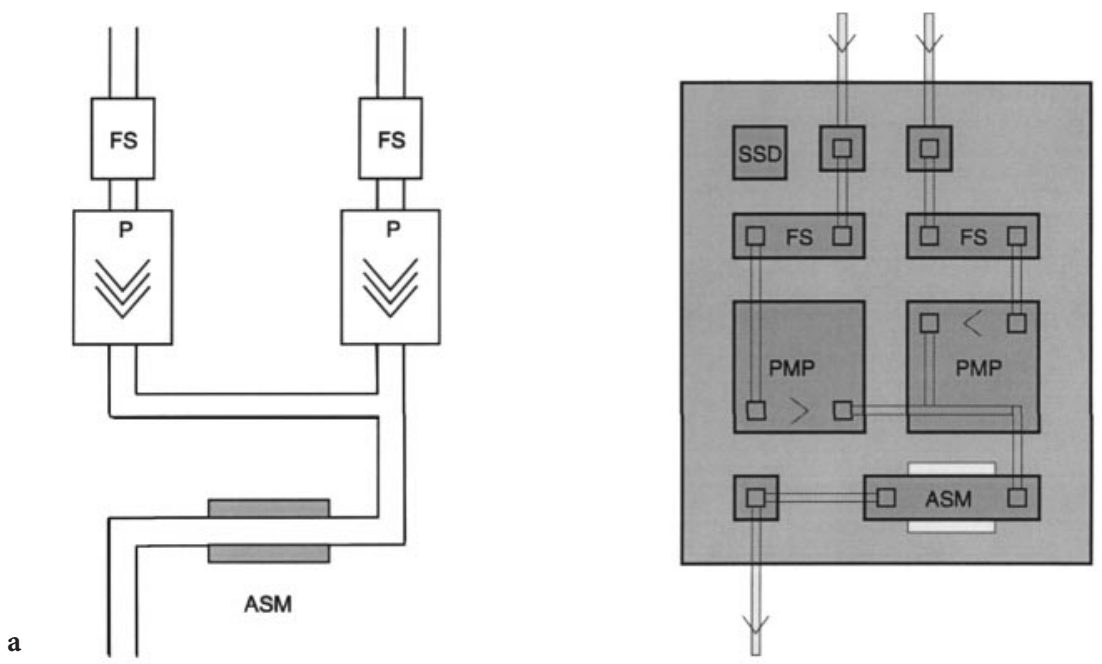

b

Fig. 24. Micro Analysis System. a Structure of NAS with two flow sensors, two pumps and an absorption sensor modul. b Component lay-out of MAS

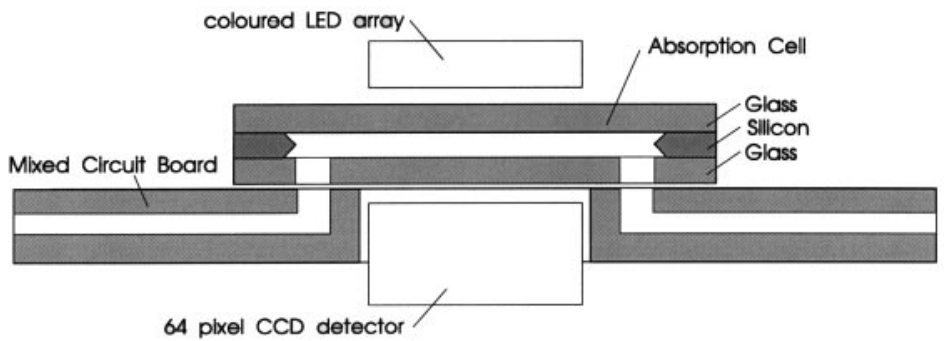

Fig. 25. Cross-section of the optical absorption detector

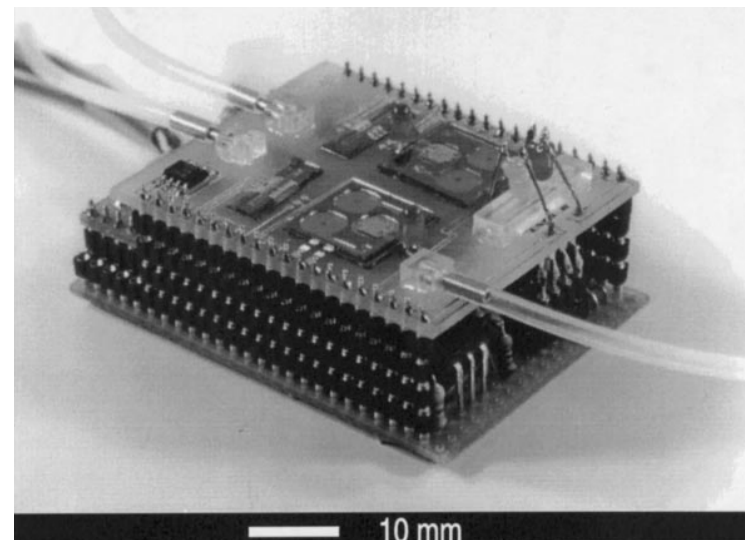

Fig. 26. Demonstrator MAS modules mounted on a $\mathrm{MCB}$ 

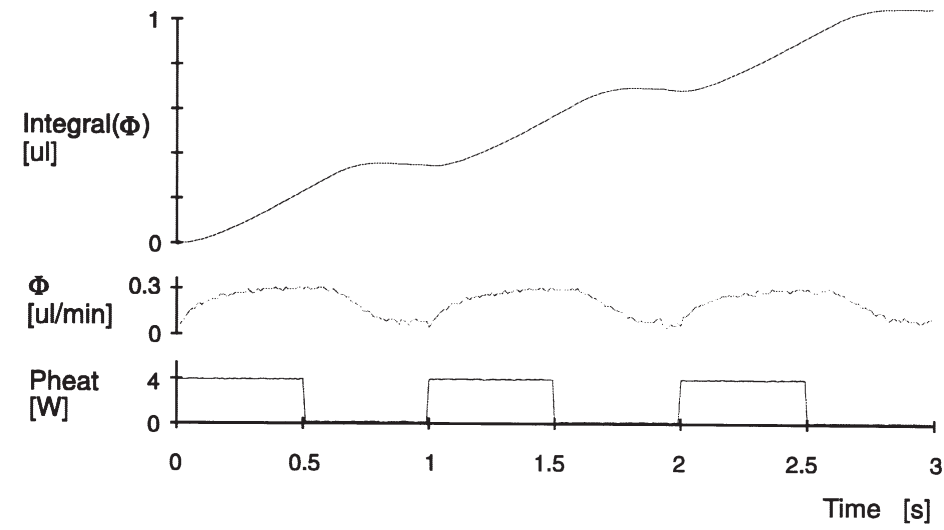

Fig. 27. Measured pump and flow sensor behavior

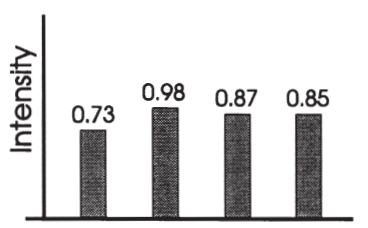

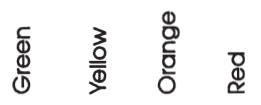

Transparant (no dye)

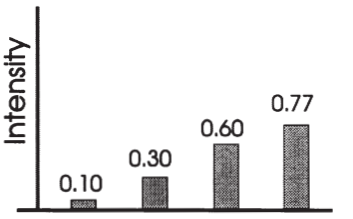

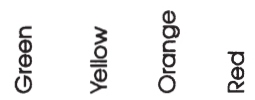

$\mathrm{Ph}=7$ (dye is red)

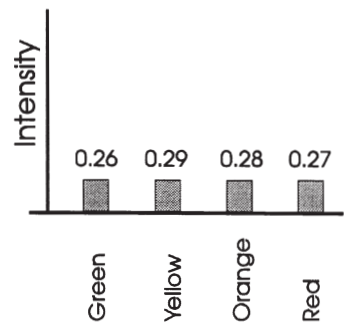

$\mathrm{Ph}=3$ (dye is blue)

Fig. 28. Measured light intensities with four colored LED's

is in accordance with the simulation results. Integration of the flow sensor signal results in a very smooth dose function.

The operation of the absorption detection is demonstrated by recording absorption intensities. This was done qualitatively at four different wavelengths for three liquids: a transparent fluid, the Congo red indicator at $\mathrm{pH}=7$ (redcolored), and the Congo red indicator at $\mathrm{pH}=3$ (blue-colored). As indicated in Fig. 28, the two differently colored states of Congo red can clearly be distinguished from each other, and from the transparent background solution. Although this demonstration is not optimized, the absorption path length for instance is only $380 \mu \mathrm{m}$ thick (thickness of a $3^{\prime \prime}$ diameter silicon wafer), it clearly illustrates the potential of this approach.

\section{4}

\section{Applications}

Miniaturized FIA-systems can be used for a variety of applications. First of all, such systems can be used to replace existing conventional FIA-systems, opera- 
ted by roller-pumps. The direct advantage is a $10-100$-fold reduction in reagent and sample consumption [44, 45]. These systems may find an interesting application for (quasi) on-line process monitoring. The continuous operation in these applications makes the reduction in consumption and waste of chemicals an important advantage.

A second application is as an autonomous instrument for environmental field measurements. The aforementioned advantages are here accompanied by a low power consumption, enabling a long stand-alone time with battery use. Although several research and development projects are actually being carried out in Europe in this direction, up to now no such miniature instrument has been commercialized.

A third application for $\mu$ TAS is in the biomedical field. Gumbrecht et al. [46, 47] developed a monolithically integrated, ISFET-based sensor system for (bedside) monitoring of blood $\mathrm{pH}, \mathrm{pO}_{2}$ and $\mathrm{pCO}_{2}$ in patients. Here the successful introduction on the market mainly depends on the price of the system, for which reason a CMOS-compatible design of the silicon part is needed. Evidently, such a development is only possible in the case of a high volume market.

In terms of space applications, the low weight accompanied by the small size gives the system a decisive advantage over conventional systems. In addition, the use of silicon processing may also give lower fabrication costs. This is, however, strongly dependent on the type of system and, as mentioned earlier, the production volume. Examples of space applications are the space micro-bioreactor as developed by van der Schoot et al. [48], and the previously mentioned sensor array system [11]. Whereas the first system is meant to be a small-size, lowpower experimentation setup for biological experiments, the second one is meant to be incorporated in the life support systems for astronauts. In this case, the light weight, small size and small power consumption are the decisive advantages of the microsystem approach.

Finally, the most promising application area of $\mu$ TAS lies in DNA analysis for two reasons. First, microstructures for capillary electrophoresis offer the

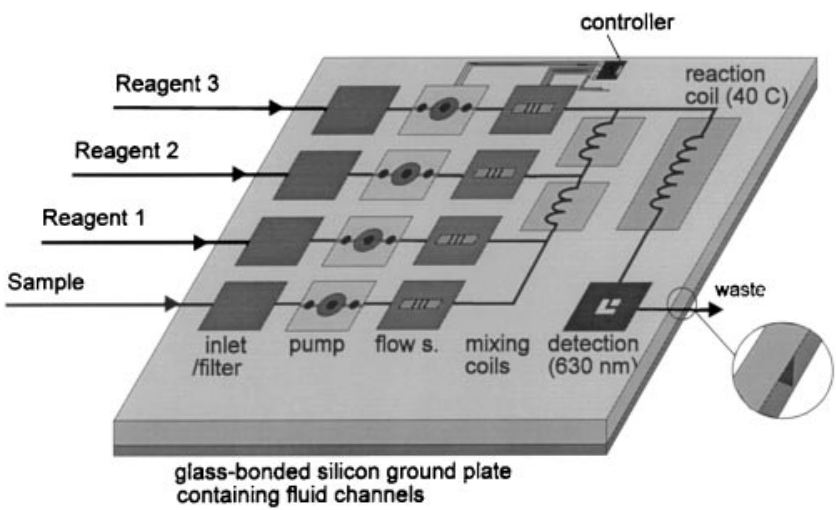

Fig. 29. Ammonia analyzing system according to the proposed MCB-concept 
advantage of a high analysis speed $[49,50]$ which is crucial for DNA-sequencing. Although most of the work on capillary-electrophoresis structures has been carried out with micromachined quartz structures, recently techniques for realization of electrically insulated structures made with silicon microtechnology have been presented, as illustrated in Sect. 2.3.3. The advantage is that microdetectors such as electrochemical, differential pressure or thermal sensors are much more easily integrated with the microchannels than with quartz structures. The second reason that makes microfabricated structures promising for DNA analysis is that they allow the manipulation of fluids in the nanoliter or even picoliter range. Recently, much work has been done on the realization of micro-titerplates for DNA screening [51-53]. Here a combination of precise fabrication of micro-volume reactors with a clever fluidic system and micro dosing (inkjet) nozzles to charge every microreactor with the appropriate chemicals yields a highly sophisticated microanalysis system with excellent marketing prospects.

\section{5}

\section{Conclusions}

In this chapter we have described the possibilities of silicon microtechnology for the realization of micro (bio)chemical analysis systems. It can be concluded that, with micro system technology, a variety of components for fluid handling on a micro scale can be realized. Etching techniques can be used for the production of planar microchannels, either in silicon or completely insulating, in silicon oxide. Utilization of micro system technology for a planar fluid-channel plate also facilitates the integration of different components into one system without connecting tubing. Using the same concept, electronic components can also be added. It has been shown that bondgraph modeling provides a valuable tool for the simulation of component and system behavior.

The value of this approach is illustrated by a demonstrator chemical analysis system ( $\mu$ FIA-system) comprising two micropumps, two flow sensors, an optical absorption cell and control electronics. The capability of detecting a differently colored $\mathrm{pH}$ indicator proves that this concept can be used for many miniaturized FIA systems. Given the number of particular properties of $\mu$ TAS such as small size, fast response, little consumption of chemicals and electrical power and, potentially, low price, a wide range of potential applications are possible. However, in order to achieve low cost production, large numbers are needed. This is best achieved by focusing efforts onto a few generic systems, that may be finely tuned for particular applications. The selection of these few generic systems appears to be the greatest challenge for the successful implementation of $\mu$ TAS. The most promising application seems to be in DNA analysis, where a combination of high analysis speed, extremely small volumes, and precise microsystem fabrication is required and which offers a potentially large market volume.

Acknowledgements. The authors wish to thank Vincent Spiering, Willem Tjerkstra, Meint de Boer and Erwin Berenschot for their valuable contributions. Parts of this work have been car- 
ried out with financial support from the Dutch Foundation for Technical Sciences (STW) and with an OSF grant from the University of Twente.

\section{6}

\section{References}

1. van den Berg A, Bergveld P (1996) Anal Meth Instr Special Issue 1996:9

2. Göpel H (1991) (ed) Sensors, A comprehensive survey, 2, VCH-Verlag, Weinheim, Germany

3. Gravesen P, Branebjerg J, Jensen OS (1993) J Micromech Microeng 3:168

4. Elwenspoek M, Lammerink TSJ, Miyake R, Fluitman JHJ (1994) J Micromech Microeng 4: 227

5. van den Berg A, van der Schoot BH, van den Vlekkert HH (1991) Ion sensitive field effect transistors. In: Sensors - A comprehensive book series in eight volumes, vol 2, chap 10.2, $\mathrm{VCH}$, Weinheim, Germany

6. Manz A, Graber N, Widmer HM (1990) Sens Actuators, B1:244

7. van der Schoot BH, Jeanneret S, van den Berg A, de Rooij NF (1993) Anal Meth Instrumentation $1(1): 38$

8. Bruns MW (1992) Proc. IEEE Int Conf Industrial Electronics Control Instrumentation 3: 1640

9. van Lintel HTC, van de Pol FCM, Bouwstra S (1988) Sens Actuators 15:153

10. van der Linden WE (1987) Trends Anal Chem 6:37

11. van Steenkiste F, Grünkorn H, Claesen L, Baert K, Hermans L, DeBruyker D, de Cooman M, Spiering V, van den Berg A, van der Schoot BH, Arquint P, Born R, Schumann K(1996) Anal Meth Instr Spec. Issue $\mu$ TAS '96:138

12. van Rijn CJM, Elwenspoek MC (1995) Proc MEMS '95, Amsterdam, The Netherlands, 83

13. Miyake R, Lammerink TSJ, Elwenpoek MC, Fluitman JHJ (1993) Proc MEMS '93, Fort Lauderdale, (FA), USA

14. Robinson TE, Justice JB (1991) Microdialysis in neurosciences, Elsevier, Amsterdam, The Netherlands

15. Laurell T, Rosengren L, Drott J (1994) In: van den Berg A, Bergveld P (eds), Micro total analysis systems, Kluwer, Dordrecht, The Netherlands, p 227

16. Künnecke W, Bilitewski U (1994) A novel sampling technique for total analysis systems In: van den Berg A, Bergveld P (eds) Micro total analysis systems, Kluwer, Dordrecht, The Netherlands, p 223

17. Kaartinen N (1996) Proc MEMS '96, San Diego, (CA), USA, 395

18. Schomburg WK, Vollmer J, Büstgens B, Fahrenberg J, Hein H, Menz W (1994) J Micromech Microeng 3:216

19. Smits JG (1990) Sens Actuators, A21 - 23: 203

20. Lammerink TSJ, Elwenspoek M, Fluitman JHJ (1993) Proc MEMS '93, Fort Lauderdale, FA, USA, 254

21. van de Pol FCM, van Lintel HTG, Elwenspoek M, Fluitman JHJ (1990) Sens Actuators A21-A23:198

22. van der Schoot BH, Jeanneret S, van den Berg A, de Rooij NF (1992) Sens Actuators B6:57

23. Gass V, van der Schoot BH, Jeanneret S, de Rooij NF (1993) Proc MME '93, Neuchâtel, Switzerland, 177

24. Shoji S, Esashi M, van der Schoot BH, de Rooij NJ (1992) Sens Actuators, A32:335

25. Zengerle R, Uhlrich J, Kluge S, Richter M, Richter A (1995) Sens Actuators A50:81

26. 20SIM, Commercially available modeling and simulation package developed at the University of Twente, Control laboratory, Faculty of Electrical Engineering, Enschede, the Netherlands

27. Zengerle R, Richter A, Sandmaier H (1990) Proc MEMS '92:19

28. Richter A, Plettner A, Hoffmann KA, Sandmaier H (1991) Sens Actuators A29:159

29. Richter A, Plettner A, Hofmann KA, Sandmayer H (1991) Proc MEMS ‘ 91 : 271

30. Bart SF, Lee S, Tavrow 1 (1990) Mehregany M, Lang J (1990) Sens Actuators, A21 -23:193 
31. Fuhr G, Hagedorn R, Müller T, Benecke W, Wagner B (1992) Proc MEMS '92:25

32. Harrison DJ, Fluri K, Seiler K, Fan Z, Effenhauser CS, Manz A (1993) Science 261:895

33. Jakobson SC, Hergenroder R, Koutny LB, Ramsey JM (1994) Anal Chem 66:1114.

34. Manz A, Harrison DJ, Verpoorte EMJ, Lüdi H, Widmer HM (1992) J Chromatogr 593:253

35. Stemme E, Stemme G (1993) Sens Actuators A39:159

36. Olsson A, Enoksson P, Stemme G, Stemme E (1995) Proc Transducers '95, Stockholm, Sweden, 291

37. Jansen HV, de Boer M, Legtenberg R, Elwenspoek M (1995) J Micromech Microeng 9:115

38. van der Schoot BH, Verpoorte EMJ, Jeanneret S, Manz A, Verpoorte NF (1994) Microsystems for analysis in flowing solutions. In: Micro total analysis systems, Kluwer, Dordrecht, The Netherlands, p 181

39. van der Schoot BH, Jeanneret S, van den Berg A, de Rooij NF (1992) Sens Actuators, B6:57

40. Fettinger JC, Manz A, Lüdi H, Widmer HM (1993) Sens Actuators, B20: 19

41. Arquint Ph, van den Berg A, van der Schoot BH, de Rooij NF, Bühler H, Morf WE (1993) Sens Actuators, B13-14:340

42. Lammerink TSJ, Tas NR, Berenschot JW, Elwenspoek MC, Fluitman JHJ (1995) Proc MEMS '95, Amsterdam, The Netherlands, 13

43. Lammerink TSJ, Spiering VL, Elwenspoek M, Fluitman JHJ, van den Berg A (1996) Proc MEMS, San Diego, USA, 389

44. van der Schoot BH, Verpoorte EMJ, Jeanneret S, Manz A, de Rooij NF (1994) Micro total analysis systems, van den Berg A, Bergveld P (eds.), Kluwer Academic Publishers, Dordrecht, The Netherlands, 181

45. van der Schoot BH, Jeanneret S, van den Berg A, de Rooij NF (1993) Anal Meth Instr 1(1): 38

46. Gumbrecht W, Abraham-Fuchs K (1996) Proc Eurosens X, Leuven, Belgium, 777

47. Gumbrecht W, Peters D, Scheller W, Erhardt W, Henke J, Steil J, Sykora U (1994) Sens Actuators B18-19:704

48. Walther I, van der Schoot BH, Jeanneret S, Arquint Ph, de Rooij NF, Gass V, Bechler B, Lorenzi G, Cogoli A (1994) J Biotechnol 38:21

49. Effenhauser CS, Manz A, Widmer HM (1995) Anal Chem 67:2284

50. Jakobson SC, Hergenröder R, Koutny LB, Ramsey JM (1994) Anal Chem 66:1114

51. Effenhauser CS, Bruin GJM, Paulus A, Ehrat M (1996) Anal Meth Instr Spec Issue $\mu$ TAS '96: 124

52. Northrup MA, Beeman B, Hadley D, Landre P, Lehew S (1996) Anal Meth Instr Spec Issue $\mu$ TAS ' $96: 153$

53. Woudenberg TM, Winn-Deen ES, Albin M (1996) Anal Meth Instr Spec Issue $\mu$ TAS '96:55 